in vivo $32: 1427-1432(2018)$

doi:10.21873/invivo.11395

\title{
Geranylgeraniol-induced Myogenic Differentiation of C2C12 Cells
}

\author{
TAKUMA MATSUBARA ${ }^{1}$, MARIKO URATA ${ }^{1}$, TSUYOSHI NAKAJIMA ${ }^{1}$, MARI FUKUZAKI $^{1}$, RYO MASUDA $^{1}$, \\ YOSHIYUKI YOSHIMOTO ${ }^{1}$, WILLIAM N. ADDISON ${ }^{2}$, CHIHIRO NAKATOMI $^{1}$, KAZMASA MORIKAWA ${ }^{3}$, \\ MIN ZHANG ${ }^{4}$, KATSURA SAEKI $^{5}$, YUKIKO TAKAHASHI ${ }^{6}$, ATSUKO NAKAMICHI ${ }^{6}$ and SHOICHIRO KOKABU ${ }^{1}$ \\ Divisions of ${ }^{1}$ Molecular Signaling and Biochemistry, ${ }^{4}$ Oral Pathology, and \\ ${ }^{5}$ Developmental Stomatognathic Function Science, Department of Health Improvement, and \\ ${ }^{6}$ School of Oral Health Sciences, Kyushu Dental University, Kitakyushu, Japan; \\ ${ }^{2}$ Research Unit, Shriners Hospitals for Children-Canada, Department of Human Genetics, \\ McGill University, Montreal, QC, Canada; \\ ${ }^{3}$ Division of Pediatric and Special Care Dentistry, Department of Developmental Oral Health Science, \\ School of Dentistry, Iwate Medical University, Morioka, Japan
}

\begin{abstract}
Background: Geranylgeraniol (GGOH) is a C20 isoprenoid found in fruits, vegetables, and grains, including rice. As a food substance, GGOH is categorized as 'Generally Recognized as Safe'. GGOH is an intermediate product in the mevalonate pathway and acts as a precursor to geranylgeranylpyrophosphate. Materials and Methods: C2C12 mouse myoblasts derived from muscle satellite cells were used. Quantitative reverse-transcriptase polymerase chain reaction, western blotting analysis, and immunocytochemical analysis were performed to respectively assess mRNA expression, protein levels, and the number of myofibers. Results: $G G O H$ reduced the expression levels of skeletal muscle atrophy-related ubiquitin ligases in myofibers derived from $\mathrm{C} 2 \mathrm{C} 12$ cells. $\mathrm{GGOH}$ induced myogenic differentiation of $\mathrm{C} 2 \mathrm{C} 12$ cells via geranylgeranylation. GGOH did not adversely affect the proliferation of $\mathrm{C} 2 \mathrm{C} 12$ cells. Conclusion: $\mathrm{GGOH}$ induces myoblast differentiation in C2C12 cells.
\end{abstract}

Satellite cells are skeletal muscle stem cells residing beneath the basal lamina that provide myonuclei for postnatal muscle growth, repair, and regeneration in adults. Satellite cells are

This article is freely accessible online.

Correspondence to: Shoichiro Kokabu, D.D.S, Ph.D., Division of Molecular Signaling and Biochemistry, Department of Health Improvement, Kyushu Dental University, 2-6-1 Kitakyushu, Fukuoka 803-8580, Japan. Tel: +81 932851131, Fax: +81 932856000, e-mail: r14kokabu@fa.kyu-dent.ac.jp

Key Words: Sarcopenia, myogenesis, statin, geranylgeranylation, $\mathrm{C} 2 \mathrm{C} 12$ cells. activated in response to muscle injury, proliferate extensively and then differentiate into myoblasts. This is accompanied by the transcriptional up-regulation of myogenic differentiation $(M Y O D)$ and other myogenic differentiation marker genes, such as myogenin $(M Y O G)$, creatine kinase M-type $(C K M)$, and myosin heavy chain (MYHC) (1-3). Insulin-like growth factors (IGFs) are essential for skeletal muscle development, regeneration, and hypertrophy - processes which all require satellite cell activation and differentiation (4-6). The autocrine action of IGF2 is especially critical for the differentiation of satellite cells in vitro (7). C2C12 cells are a murine myoblast cell line derived from satellite cells (8). C2C12 cells are commonly used as an in vitro model of muscle regeneration due to their ability to transition from a proliferative phase into differentiated myofibers, similar to satellite cells, upon adequate stimulus (3).

Statins act by inhibiting 3-hydroxy-3-methylgutarylcoenzyme A reductase, the first step of the isoprenoid biosynthetic pathway and the rate-limiting step of cholesterol biosynthesis (9). Statins are used as a frontline therapy for lowering plasma cholesterol and preventing cardiovascular disease (10-13). Statins are generally safe and effective. However, they may induce a variety of skeletal muscleassociated, dose-dependent adverse reactions that range from muscle pain to muscle cell damage and severe rhabdomyolysis (14-17). These statin-associated muscle side-effects are prevalent in about $10 \%$ of patients (18). Statin-associated muscle disorders are likely due to inhibition of the synthesis of crucial intermediary molecules such as geranylpyrophosphate and geranylgeranylpyrophosphate (GGPP) (19-21). Treatment of $\mathrm{C} 2 \mathrm{C} 12$ cells with GGPP was found to reverse the suppressive effect of statin on myotube formation (22). Geranylgeraniol (GGOH), a precursor to GGPP, reduced 
muscle cell damage induced by statin treatment in vitro (23). Thus, GGOH seems to have protective effects on skeletal muscle. However, the extent of this potentially beneficial effect remains unknown. In this study, the effect of GGOH on myogenesis in $\mathrm{C} 2 \mathrm{C} 12$ cells was investigated.

\section{Materials and Methods}

Cell culture, transfection, and skeletal muscle differentiation. C2C12 murine myoblasts were purchased from American Type Culture Collection (Manassas, VA, USA). C2C12 cells were maintained as previously described (24) and cultured in the presence of $0,5,10,50$, or $100 \mu \mathrm{M}$ GGOH (Sigma-Aldrich Chemicals, St. Louis, MO, USA) and $100 \mu \mathrm{M}$ of the geranylgeranyltransferase I inhibitor $N$-[4-[2(R)-amino-3-mercaptopropyl]amino-2-(1-naphthalenyl)benzoyl]-L-leucine methyl ester trifluoroacetate salt (GGTI298) (Tocris Bioscience, Bristol, UK). Skeletal muscle differentiation in $\mathrm{C} 2 \mathrm{C} 12$ cells was induced by culturing cells with Dulbecco's modified Eagle's medium supplemented with $2 \%$ horse serum (Biosera, Kansas City, MO, USA) for 5-8 days (3).

Reverse transcription and quantitative polymerase chain reaction $(q P C R)$ analysis. Total RNA was isolated from $\mathrm{C} 2 \mathrm{C} 12$ cells using FastGene RNA Basic Kit (Nippon Genetics, Tokyo, Japan) and then reverse-transcribed into cDNA using the ReverTra Ace qPCR RT Kit (Toyobo, Osaka, Japan). SYBR green-based qPCR was performed in 96-well plates using PowerUp SYBR Green Master Mix (ThermoFisher Scientific, Waltham, MA, USA) with QuantStudio 3 Real-Time PCR System (ThermoFisher Scientific). Values were normalized to $\beta$-actin (Actb) using the $2^{-\Delta \Delta C t}$ method (25). The following primers were used for qPCR analyses: qPCR for murine Fbxo32: forward: agtgaggaccggctactgtg, reverse: gatcaaacgcttgcgaatct; tripartite motif containing 63 (Trim63): forward: tgacatctacaagcaggagtgc, reverse: tcgtcttcgtgttccttgc; murine Igf2: forward: cctccttacccaacttcaggt, reverse: aagagatgagaagcac caacatc; murine Myog: forward: ccttgctcagctccctca, reverse: tgggagttgcattcactgg; murine Myod: forward: agcactacagtggcgactca, reverse: ggccgctgtaatccatcat; murine $\mathrm{Ckm}$ : forward: cagcacagacag acactcagg, reverse: gaacttgttgt gggtgttgc; and murine Actb: forward: aaggccaaccgtgaaaagat, reverse: gtggtacgaccagaggcatac.

Proliferation assay. $\mathrm{C} 2 \mathrm{C} 12$ cells were cultured in the presence of $\mathrm{GGOH}$ at concentrations of $0,5,10,50$, or $100 \mu \mathrm{M}$ for 1,2 , or 3 days. Proliferation of $\mathrm{C} 2 \mathrm{C} 12$ cells was assessed using Cell Counting Kit-8 (Dojindo, Kumamoto, Japan), according to the manufacturer's protocol.

ImmunocytochemicaI analysis. C2C12 cells were fixed by $4 \%$ formaldehyde for $10 \mathrm{~min}$ and incubated with primary antibodies for 1 hour at room temperature following blocking/permeabilization with phosphate-buffered saline containing $0.3 \%$ Triton X100 and $5 \%$ goat serum for $30 \mathrm{~min}$ at room temperature. Mouse monoclonal antibody to MYHC (R \& D Systems, Minneapolis, MN, USA) was used for immunocytochemistry. The target protein was visualized using an Alexa 488-conjugated secondary antibody (Invitrogen, Carlsbad, CA, USA) and imaged with an ABZ-9000 microscope (Keyence, Tokyo, Japan).

Western blot analysis. The following mouse monoclonal antibodies were used for western blot analysis: anti-MYOG (Santa Cruz
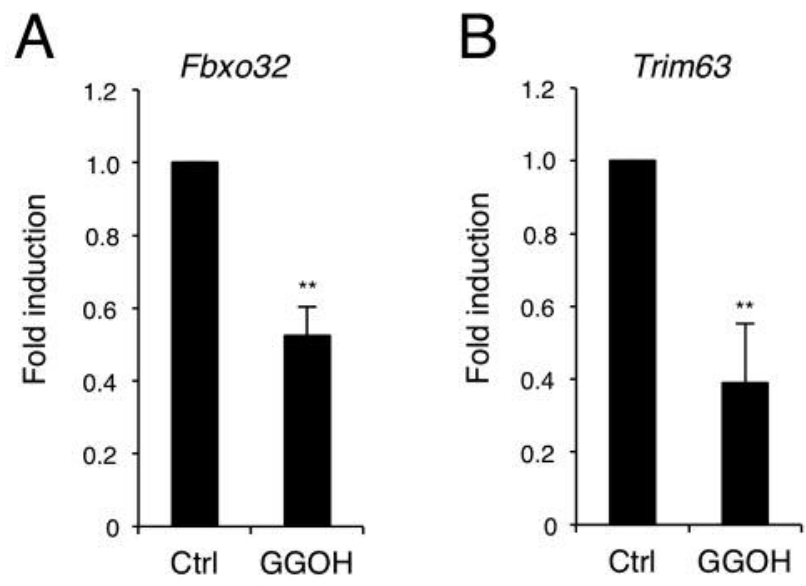

Figure 1. Geranylgeraniol (GGOH) reduces the expression levels of skeletal muscle atrophy-related ubiquitin ligases in myofibers derived from C2C12 cells. C2C12 cells were cultured with $2 \%$ horse serum for 5 days and then treated with or without (CtrI) $50 \mu M$ GGOH for another 3 days. Total RNA was isolated, then F-box protein 32 (Fbxo32) (A) and tripartite motif containing 63 (Trim63) (B) mRNA levels were analyzed using quantitative polymerase chain reaction. All data are expressed as the mean $\pm S D(n=3)$. *Significantly different at $p<0.01$ versus vehicle-treated cells. Similar results were obtained by three independent experiments.

Biotechnology, Santa Cruz, CA, USA), anti-MYHC (R \& D systems), and anti-ACTB (Sigma-Aldrich Chemicals). The target proteins were detected using an anti-mouse or anti-rabbit IgG antibody conjugated with a horseradish peroxidase (Cell Signaling, Beverly, MA, USA) and visualized by using ImmunoStar LD (WAKO, Osaka, Japan).

Statistical analysis. Comparisons were made using an unpaired Student's $t$-test; the results are shown as the means \pm S.D. Statistical significance was defined as $p<0.05$.

\section{Results}

Firstly, it was confirmed whether GGOH protects skeletal muscle fibers derived from $\mathrm{C} 2 \mathrm{C} 12$ cells from atrophy. Treatment of cells with $50 \mu \mathrm{M}$ GGOH for 3 days reduced the expression levels of muscle atrophy-related ubiquitin ligase Fbxo32 (Figure 1A) and Trim63 (Figure 1B).

Next, we examined the effect of GGOH on skeletal muscle differentiation in $\mathrm{C} 2 \mathrm{C} 12$ cells. qPCR analysis revealed that although $50 \mu \mathrm{M}$ GGOH treatment for 2 days did not change the expression level of Myod (Figure 2A), it did enhance the induction of early-stage myogenic marker genes such as $\mathrm{Myog}$ and $\mathrm{Ckm}$ (Figure 2B and $\mathrm{C}$ ). GGOH treatment also led to a dose-dependent increase in the protein level of MYOG (Figure $2 \mathrm{~F}$ ) as well as of the late myoblast marker MYHC (Figure 2G and $\mathrm{H}$ ). In addition, GGOH dramatically stimulated the expression level of $\operatorname{Ig} f 2$ in $\mathrm{C} 2 \mathrm{C} 12$ cells (Figure 2D). The 


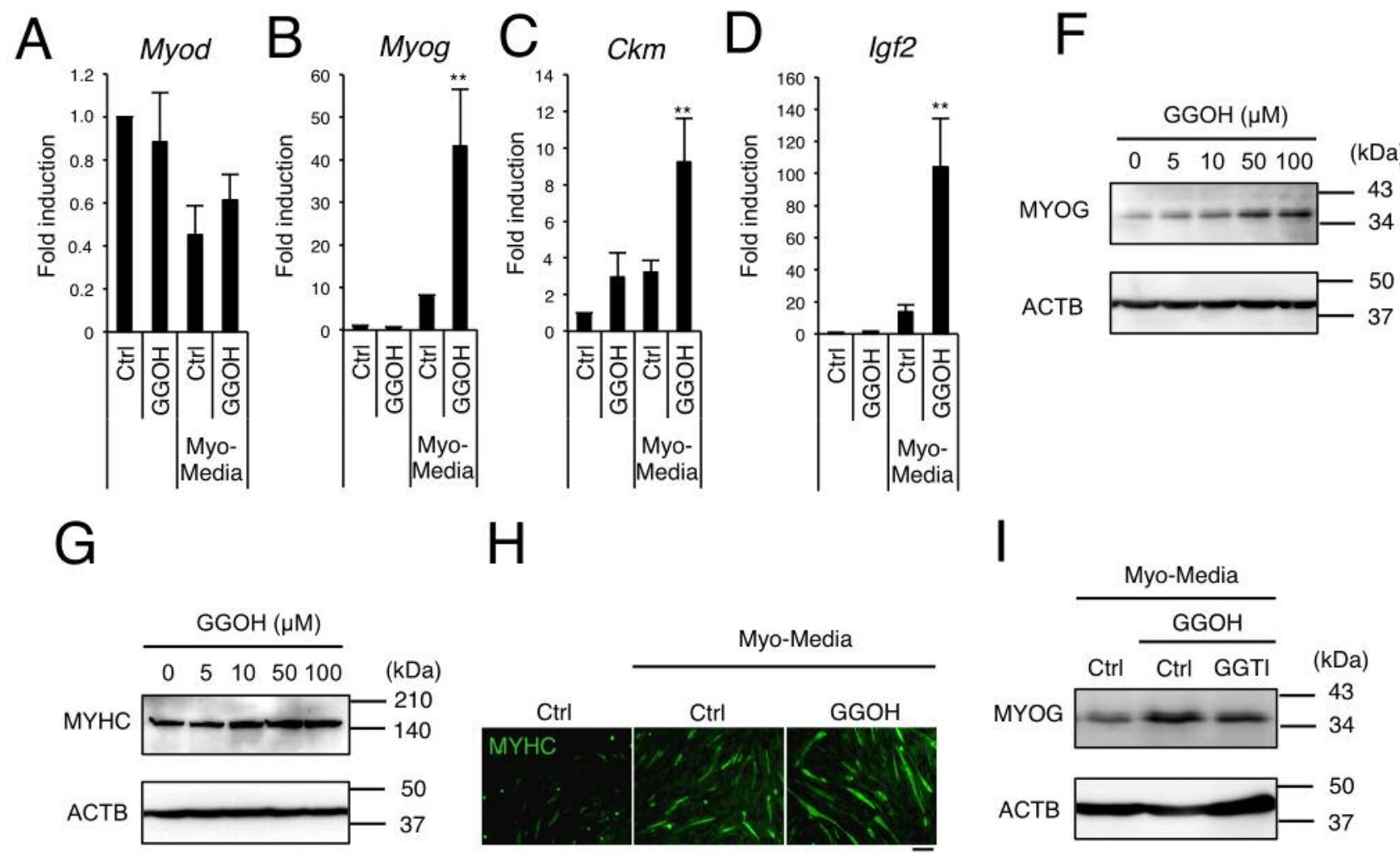

Figure 2. Geranylgeraniol (GGOH) induces myogenic differentiation of $\mathrm{C} 2 \mathrm{C} 12$ cells via geranylgeranylation. C2C12 cells were treated with or without (CtrI) $50 \mu \mathrm{M}$ GGOH for 2 days. Myogenic differentiation (Myod) (A), myogenin (Myog) (B), creatine kinase, M-type (Ckm) (C), and insulinlike growth factor-2 (Igf2) (D) mRNA levels were analyzed using quantitative polymerase chain reaction. All data are expressed as the mean $\pm S D$ $(n=3) . *$ Significantly different at $p<0.01$ versus vehicle-treated cells. Cells were treated with $0,5,10$, 50, or $100 \mu M G G O H$ for $3(F)$ or $5(G)$ days. The protein levels of MYOG $(F)$ and myosin heavy chain $(M Y H C)(G)$ were assessed by western blotting analysis. Immunocytochemical analysis was performed using antibody to MYHC on day 5. Scale bar represents $10 \mu \mathrm{m}(\mathrm{H})$. Cells were treated with or without $50 \mu M$ GGOH in the presence or absence of $100 \mu M$ GGTI-298 for 3 days. The protein levels of MYOG were determined by western blotting analysis (I). Similar results were obtained by three independent experiments (F-I). Myogenic differentiation of C2C12 cells was induced by the treatment with Dulbecco's modified Eagle's medium supplemented with $2 \%$ horse serum (Myo-Media) (A-F).

positive effect of GGOH on the induction of Myog was blocked by the addition of the geranylgeranyl transferase inhibitor GGIT-298 (Figure 2I), suggesting that the augmentative effect of GGOH on myogenic differentiation is via geranlygeranylation. GGOH did not adversely affect the proliferation of $\mathrm{C} 2 \mathrm{C} 12$ cells (Figure 3 ).

\section{Discussion}

In the present study, we examined the effect of GGOH on fiber degradation, differentiation, and proliferation in $\mathrm{C} 2 \mathrm{C} 12$ cells.

$\mathrm{GGOH}$ is a $\mathrm{C} 20$ isoprenoid found in fruits, vegetables, and grains, including rice. As a food substance, GGOH is categorized as 'Generally Recognized as Safe' (26). GGOH is an intermediate product in the mevalonate pathway and acts as a precursor to GGPP. In the cell, GGOH is thought to be subsequently converted into the pyrophosphate moiety, GGPP, by two successive monophosphorylation events (27). GGPP induces geranylgeranylation, which is necessary for the membrane localization of intracellular proteins, particularly the small GTP-binding proteins rat sarcoma virus oncogene (RAS), ras homolog family member (RHO), Rac family small GTPase (RAC) and Rap GTPase (RAP) (28). In our study, GGTI-298, an inhibitor of geranylgeranylation, eliminated $\mathrm{GOOH}$-induced myoblast differentiation of $\mathrm{C} 2 \mathrm{C} 12$ cells (Figure 2I), suggesting that GGOH-induced myogenesis requires geranylgeranylation of certain protein(s). Further experiments are needed to elucidate the mechanism that underlies GGOH-induced myoblast differentiation.

Inhibition of the isoprenoid biosynthetic pathway by statins may be involved in the occurrence of statin-associated 


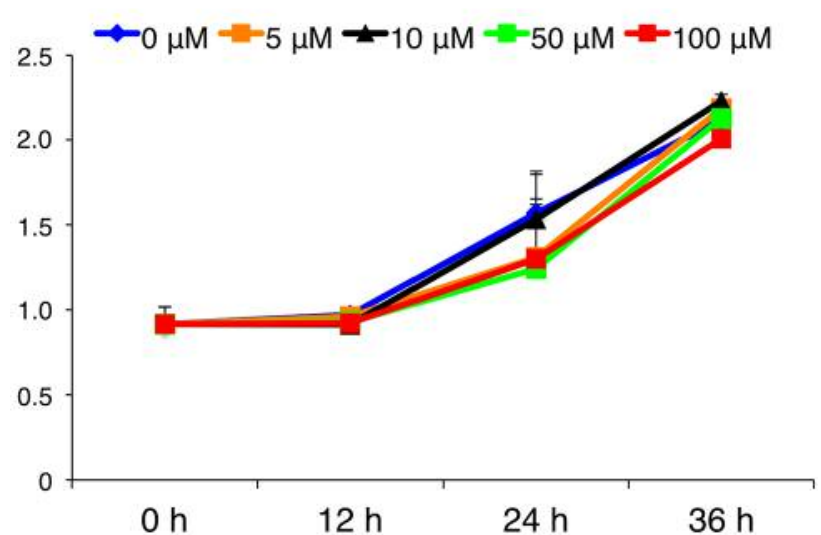

Figure 3. Geranylgeraniol (GGOH) does not affect the proliferation of C2C12 cells. C2C12 cells were cultured in the presence of $0,5,10,50$, or $100 \mu \mathrm{MGGOH}$ for the indicated times. The proliferation of cells was assessed using a Cell Counting Kit-8. All data are expressed as the mean $\pm S D(n=3)$.

muscle problems $(19,21)$, suggesting that GGOH may be a potential drug for the prevention or treatment of statinassociated muscle problems without interfering with the beneficial plasma cholesterol-lowering effects of statins.

Skeletal muscle atrophy, such as observed during sarcopenia, is characterized by an associated loss of skeletal muscle mass and a decrease in muscle strength that impairs healthy life expectancy (29). The prevalence of sarcopenia is approximately $10 \%$ among adults aged 60 years or older (30), resulting in a cost of over US\$18 billion in 2001 alone (31). Thus, there is an unmet and urgent need for strategies that will prevent the loss of skeletal muscle fibers and stimulate the proliferation and differentiation of skeletal muscle stem cells such as satellite cells for improving skeletal muscle mass and function.

In conclusion, we demonstrated that in $\mathrm{C} 2 \mathrm{C} 12$ murine skeletal muscle myoblasts cells, GGOH reduced the expression of muscle atrophy-related genes and enhanced myogenic differentiation. Since GGOH is categorized as 'Generally Recognized as Safe' and can be taken orally (32), upon the establishment of a suitable protocol for $\mathrm{GGOH}$ treatment, our data will provide the basis for a new potential product for the treatment of muscle atrophy.

\section{Conflicts of Interest}

The Authors declare that they have no conflict of interests in regard to this study.

\section{Acknowledgements}

This study was supported by The Japan Health Foundation (S. K.).

\section{References}

1 Montarras D, L'Honore A, and Buckingham M: Lying low but ready for action: the quiescent muscle satellite cell. FEBS J 280: 4036-4050, 2013.

2 Zammit PS, Golding JP, Nagata Y, Hudon V, Partridge TA, and Beauchamp JR: Muscle satellite cells adopt divergent fates: A mechanism for self-renewal? J Cell Biol 166: 347-357, 2004.

3 Kokabu S, Nakatomi C, Matsubara T, Ono Y, Addison WN, Lowery JW, Urata M, Hudnall AM, Hitomi S, Nakatomi M, Sato T, Osawa K, Yoda T, Rosen V, and Jimi E: The transcriptional co-repressor TLE3 regulates myogenic differentiation by repressing the activity of the MyoD transcription factor. J Biol Chem 292: 12885-12894, 2017.

4 Florini JR, Ewton DZ, and Magri KA: Hormones, growth factors, and myogenic differentiation. Annu Rev Physiol 53: 201-216, 1991

5 Rosenblatt JD, Yong D, and Parry DJ: Satellite cell activity is required for hypertrophy of overloaded adult rat muscle. Muscle Nerve 17: 608-613, 1994.

6 Barton-Davis ER, Shoturma DI, and Sweeney HL: Contribution of satellite cells to IGF-I induced hypertrophy of skeletal muscle. Acta Physiol Scand 167: 301-305, 1999.

7 Florini JR, Magri KA, Ewton DZ, James PL, Grindstaff K, and Rotwein PS: "Spontaneous" differentiation of skeletal myoblasts is dependent upon autocrine secretion of insulin-like growth factor-II. J Biol Chem 266: 15917-15923, 1991.

8 Yaffe D and Saxel O: Serial passaging and differentiation of myogenic cells isolated from dystrophic mouse muscle. Nature 270: 725-727, 1977.

9 Endo A, Tsujita Y, Kuroda M, and Tanzawa K: Inhibition of cholesterol synthesis in vitro and in vivo by ML-236A and ML236B, competitive inhibitors of 3-hydroxy-3-methylglutarylcoenzyme A reductase. Eur J Biochem 77: 31-36, 1977.

10 Tikkanen MJ and Nikkila EA: Current pharmacologic treatment of elevated serum cholesterol. Circulation 76: 529-533, 1987.

11 Illingworth DR and Sexton GJ: Hypocholesterolemic effects of mevinolin in patients with heterozygous familial hypercholesterolemia. J Clin Invest 74: 1972-1978, 1984.

12 Hoeg JM, Maher MB, Zech LA, Bailey KR, Gregg RE, Lackner KJ, Fojo SS, Anchors MA, Bojanovski M, Sprecher DL, and Brewer HB Jr.: Effectiveness of mevinolin on plasma lipoprotein concentrations in type II hyperlipoproteinemia. Am J Cardiol 57: 933-939, 1986.

13 Grundy SM and Vega GL: Influence of mevinolin on metabolism of low density lipoproteins in primary moderate hypercholesterolemia. J Lipid Res 26: 1464-1475, 1985.

14 Thompson PD, Clarkson P, and Karas RH: Statin-associated myopathy. Jama 289: 1681-1690, 2003.

15 Pasternak RC, Smith SC Jr., Bairey-Merz CN, Grundy SM, Cleeman JI, Lenfant C, American College of C, American Heart A, National Heart L and Blood I: ACC/AHA/NHLBI Clinical Advisory on the Use and Safety of Statins. Circulation 106: 1024-1028, 2002.

16 McKenney JM, Davidson MH, Jacobson TA, Guyton JR, and National Lipid Association Statin Safety Assessment Task F: Final conclusions and recommendations of the National Lipid Association Statin Safety Assessment Task Force. Am J Cardiol 97: 89C-94C, 2006.

17 Sathasivam S: Statin induced myotoxicity. Eur J Intern Med 23: 317-324, 2012. 
18 Venero CV and Thompson PD: Managing statin myopathy. Endocrinol Metab Clin North Am 38: 121-136, 2009.

19 Bhardwaj S, Selvarajah S, and Schneider EB: Muscular effects of statins in the elderly female: A review. Clin Interv Aging 8: 47-59, 2013.

20 Nishimoto T, Tozawa R, Amano Y, Wada T, Imura Y, and Sugiyama Y: Comparing myotoxic effects of squalene synthase inhibitor, T-91485, and 3-hydroxy-3-methylglutaryl coenzyme A (HMG-CoA) reductase inhibitors in human myocytes. Biochem Pharmacol 66: 2133-2139, 2003.

21 Matzno S, Yamauchi T, Gohda M, Ishida N, Katsuura K, Hanasaki Y, Tokunaga $\mathrm{T}$, Itoh $\mathrm{H}$, and Nakamura $\mathrm{N}$ : Inhibition of cholesterol biosynthesis by squalene epoxidase inhibitor avoids apoptotic cell death in L6 myoblasts. J Lipid Res 38: 1639-1648, 1997.

22 Baba TT, Nemoto TK, Miyazaki T, and Oida S: Simvastatin suppresses the differentiation of $\mathrm{C} 2 \mathrm{C} 12$ myoblast cells via a RAC pathway. J Muscle Res Cell Motil 29: 127-134, 2008.

23 Cao P, Hanai J, Tanksale P, Imamura S, Sukhatme VP, and Lecker SH: Statin-induced muscle damage and atrogin-1 induction is the result of a geranylgeranylation defect. FASEB J 23: 2844-2854, 2009.

24 Kokabu S, Ohte S, Sasanuma H, Shin M, Yoneyama K, Murata E, Kanomata K, Nojima J, Ono Y, Yoda T, Fukuda T, and Katagiri T: Suppression of BMP-SMAD signaling axis-induced osteoblastic differentiation by small C-terminal domain phosphatase 1, a Smad phosphatase. Mol Endocrinol 25: 474$481,2011$.

25 Livak KJ and Schmittgen TD: Analysis of relative gene expression data using real-time quantitative PCR and the 2(-Delta Delta C(T)) Method. Methods 25: 402-408, 2001.

26 Muraguchi T, Okamoto K, Mitake M, Ogawa H, and Shidoji Y: Polished rice as natural sources of cancer-preventing geranylgeranoic acid. J Clin Biochem Nutr 49: 8-15, 2011.
27 Frenkel J, Rijkers GT, Mandey SH, Buurman SW, Houten SM, Wanders RJ, Waterham HR, and Kuis W: Lack of isoprenoid products raises ex vivo interleukin-1 beta secretion in hyperimmunoglobulinemia D and periodic fever syndrome. Arthritis Rheum 46: 2794-2803, 2002.

28 Walker K and Olson MF: Targeting Ras and Rho GTPases as opportunities for cancer therapeutics. Curr Opin Genet Dev 15: 62-68, 2005.

29 Delmonico MJ, Harris TB, Lee JS, Visser M, Nevitt M, Kritchevsky SB, Tylavsky FA, Newman AB, Health A, and Body Composition S: Alternative definitions of sarcopenia, lower extremity performance, and functional impairment with aging in older men and women. J Am Geriatr Soc 55: 769-774, 2007.

30 Cruz-Jentoft AJ, Baeyens JP, Bauer JM, Boirie Y, Cederholm T, Landi F, Martin FC, Michel JP, Rolland Y, Schneider SM, Topinkova E, Vandewoude M, Zamboni M, and European Working Group on Sarcopenia in Older P: Sarcopenia: European consensus on definition and diagnosis: Report of the European Working Group on Sarcopenia in Older People. Age Ageing 39: 412-423, 2010.

31 Janssen I, Shepard DS, Katzmarzyk PT, and Roubenoff R: The healthcare costs of sarcopenia in the United States. J Am Geriatr Soc 52: 80-85, 2004.

32 Giriwono PE, Shirakawa H, Ohsaki Y, Hata S, Kuriyama H, Sato $\mathrm{S}$, Goto $\mathrm{T}$, and Komai M: Dietary supplementation with geranylgeraniol suppresses lipopolysaccharide-induced inflammation via inhibition of nuclear factor-kappaB activation in rats. Eur J Nutr 52: 1191-1199, 2013.

Received August 15, 2018

Revised September 20, 2018

Accepted September 26, 2018 